\title{
Qualidade de vida em pacientes com sequelas de queimaduras*
}

\section{Quality of life of patients with after effects from burns}

\author{
Jussara de Lucena Alves ${ }^{1}$ • Emanuela Batista Ferreira e Perreira² • Priscilla Tereza Lopes de Souza ${ }^{3} \bullet$ \\ Bruna Gabrielle de Souza Costa ${ }^{4}$ Chrystenise Valéria Ferreira Paes ${ }^{5}$
}

\begin{abstract}
RESUMO
Analisar a qualidade de vida (QV) de pacientes que se queimaram e desenvolveram sequelas. Estudo transversal, quantitativo, realizado em agosto e setembro de 2014, com 43 pacientes. A QV foi avaliada pela escala Burn Specific Health Scale-Revised (PSHS-R). Sua distribuição entre os domínios foi feita através do teste de Kruskal-Wallis e Mann-Whitney, com significância de 5\%. A QV dos pacientes analisados estava prejudicada, em mais da metade. 0 domínio que apresentou pior resultado foi a "sensibilidade da pele" seguida do "trabalho". A QV desses pacientes é afetada pelas mudanças relacionadas ao tratamento e a reabilitação, tornando necessário a atuação de uma equipe multidisciplinar.
\end{abstract}

Palavras-chave: Qualidade de vida; Queimaduras; Sequelas.

\section{ABSTRACT}

To analyze the quality of life (QOL) of pactients who developed sequelae and burns. Cross-sectional and quantitative study conducted in August and September 2014, with 43 patients. QOL was evaluated by the scale Burn Specitic Health Scale Revised (PSHS-R). Their distribution between the domains was performed using the Kruskal-Wallis and Mann-Whitney test, 5\% significance. The QOL of the patients studied was impaired in more than half. The domain that presented the worst result was a "sensitive skin" followed by "word". Patients QOL is affected by changes related to treatment and rehabilitation, making necessary the work of a multidisciplinary team.

Keywords: Quality of life; Burns; Sequelae.

${ }_{1}^{1}$ Enfermeira. Especialista em Emergência Geral em caráter de residência no Hospital da Restauração, Recife-PE. Especialista em Saúde Pública pela Universidade de Pernambuco. Enfermeira assistencial do Hospital Universitário Profo Alberto Antunes, Maceió-AL. jussaradelucena@gmail.com

${ }^{2}$ Doutoranda em Cirurgia pela Universidade de Federal de Pernambuco. Enfermeira assistencial da Secretaria de Saúde de Pernambuco- Hospital da Restauração.emanuela. pereira@upe.br

${ }_{3}^{3}$ Enfermeira. Universidade Federal de Campina Grande. Residente em Terapia Intensiva no Hospital da Restauração. Recife-PE-Brasil.priscillasouza_@hotmail.com

${ }^{4}$ Enfermeira. Mestranda em Enfermagem pela Universidade Federal de Alagoas. Especialista em Cuidados Paliativos e Oncologia. Enfermeira assistencial do Hospital Universitário Profo Alberto Antunes, Maceió-AL.brunagabrielle17@hotmail.com

${ }^{5}$ Enfermeira. Especialista em Saúde Pública e Gestão em Saúde. Atua no Hospital Universitário Profo Alberto Antunes, Maceió-AL.chryspaes@gmail.com

*Artigo extraído do Trabalho de Conclusão da Residência, intitulado: Qualidade de vida em pacientes com sequelas de queimaduras. Universidade de Pernambuco UPE, 2014 Autor Correspondente: Jussara Alves de Lucena. Universidade de Pernambuco. Endereço: Rua Pe Manoel da Nóbrega, 195, Bairro São Francisco. Caruaru-PE.

E-mail: jussaradelucena@gmail.com 


\section{INTRODUÇÃO}

Queimaduras são injurias teciduais provocadas por diferentes agentes podendo resultar em lesões superficiais ou profundas; e a gravidade depende de fatores como extensão, profundidade e localização das lesões ${ }^{1}$.

Estima-se que ocorrem 40.000 internações e 4.300 óbitos por ano decorrentes de queimaduras nos Estados Unidos $^{2}$. A Sociedade Brasileira de Queimaduras ${ }^{3}$ lista como os principais agentes causadores de queimaduras, os líquidos superaquecidos, combustível, chama direta, eletricidade, agentes químicos, fogos de artifício, entre outros. Esses agentes podem atuar nos tecidos de revestimento do corpo causando destruição parcial ou total da pele e seus anexos.

No Brasil, as queimaduras têm alta relevância na morbidade da população, um estudo mostrou que em apenas um ano ocorreram cerca de 80.607 internações por lesões decorrentes de queimaduras no sistema público de saúde, o que representou, aproximadamente, $9 \%$ do total de atendimentos por causas externas. Esse agravo ainda permanece negligenciado, principalmente, em países de média e baixa renda 4 .

As queimaduras podem ser acuradas pela gravidade e prognóstico das lesões, sendo definidas pela avaliação do agente causal, profundidade, extensão da superfície corporal queimada (SCQ) e localização. É por intermédio desses fatores que se define a necessidade de internação hospitalar e se determina se as sequelas são transitórias ou permanentes ${ }^{5}$.

Define-se sequela de queimadura como qualquer alteração da pessoa vítima desta a nível estético, funcional e psicológico, como exemplo, o absenteísmo na escola e dificuldades de relacionamento social e no trabalho, em alguns casos, esta forma de trauma pode resultar em drásticas desfigurações físicas e estéticas ${ }^{6}$. 0 processo de cicatrização das queimaduras varia, podendo durar meses ou anos, dependendo da profundidade e dos demais fatores relacionados, predispondo a formação de cicatrizes hipertróficas e contraturas. Por isso, exigem um tratamento global de reabilitação, esse processo visa minimizar sequelas como cicatrizes, contraturas e outros que possam limitar a função física ${ }^{7}$.

As limitações após o trauma resultam em prejuízo à QV dos pacientes, isso decorrente das desvantagens em suas atividades diárias, interrupção do trabalho, tempo gasto com o tratamento, aspectos psicossociais, além da aceitação e adaptação à nova realidade ${ }^{8}$. A QV é a maneira como o indivíduo consegue lidar com suas necessidades pessoais; e depende de vários fatores que devem estar em equilíbrio, são eles: classe social, infraestrutura de moradia, conforto e estado de saúde?.

Evidencia-se que no Brasil as queimaduras representam um significativo agravo à saúde pública, principalmente as lesões que resultaram em sequelas, pois afetam não só o setor saúde, mas também a qualidade de vida da pessoa acometida, e apesar dos avanços científico-tecnológicos, a eficácia dos tratamentos continua insatisfatória, mostrando que mais pesquisas são necessárias para minimizar as sequelas ${ }^{8}$.

Assim, objetivou-se analisar a qualidade de vida dos pacientes adultos que sofreram queimaduras e desenvolveram sequelas, através da escala Burn Specific Health Scale-Revised (versão brasileira), em um hospital de referência em emergência no Nordeste brasileiro.

Devido à ausência de estudos mais recentes acerca da QV de pacientes com sequelas de queimaduras, é importante compreender o impacto que elas representam no estado de saúde desses indivíduos.

\section{MÉTODO}

Trata-se de estudo descritivo transversal, com abordagem quantitativa. A amostra do estudo foi composta por 43 indivíduos que estavam em tratamento no ambulatório de fisioterapia para queimados em um Hospital de Emergência referência para o Norte/Nordeste, no período de agosto e setembro de 2014.

Realizou-se a pesquisa com todos os pacientes que corresponderam aos critérios pré-estabelecidos, definidos por: ambos os sexos; maiores de 18 anos; que apresentavam sequela decorrente de queimadura de $2^{\circ}$ e $3^{\circ}$ graus; que aceitaram participar da pesquisa mediante assinatura do TCLE. Foram excluídos da pesquisa 05 pacientes com distúrbio psiquiátrico diagnosticado previamente.

Para coleta dos dados foi aplicada a escala Burn Specific Health Scale-Revised (PSHS-R): versão brasileira, validado por Ferreira $(2006)^{7}$, que consiste em 31 itens, divididos em 6 domínios: (1) Afeto e Imagem corporal (oito itens); (2) Sensibilidade da pele (cinco itens); (3) Habilidades para funções simples (quatro itens); (4) Tratamento (cinco itens); (5) Trabalho (quatro itens) e (6) Relações interpessoais (cinco itens). Para cálculo dos escores, deve-se somar, individualmente, os itens de cada domínio e dividir este total pelo número de itens do respectivo domínio. Altos valores indicam piores estados de saúde. Para mensuração das variáveis sociodemográficas e clínicas foi aplicado um questionário construído segundo o estudo de Ferreira7.

Para análise dos dados foi construído um banco na planilha eletrônica Microsoft Excel, a qual foi exportada para o software SPSS, versão 18, onde foi realizada a análise estatística. Para avaliar o perfil pessoal dos pacientes foram calculadas as frequências percentuais e construídas as respectivas distribuições de frequência. Na avaliação da qualidade vida foi aplicado o questionário PSHS-R e construídos os escores para os domínios avaliados a partir das somas dos itens de cada domínio.

A análise dos itens e dos domínios foi feita através das estatísticas: intervalo de variação, mediana, média e desvio padrão. Foram calculados os intervalos com $95 \%$ de confiança para as médias estimadas. A distribuição da QV entre os domínios avaliados foi feita através do teste de Kruskal- 
Wallis. Quando verificada diferença significativa, aplicou-se a comparação da qualidade entre os domínios, dois a dois, através do teste de Mann-Whitney. Todas as conclusões foram tiradas considerando um nível de significância de 5\%.

Por se tratar de uma pesquisa realizada com seres humanos, foram respeitados os princípios éticos, estabelecidos pela resolução 466/12 do Conselho Nacional de Saúde (CNS) que regulamenta normas para as pesquisas com seres humanos e segue os princípios básicos da bioética. A anuência da pesquisa foi dispensada pelo gestor da Instituição e, em seguida, o projeto submetido à Plataforma Brasil e enviado ao Comitê de Ética e Pesquisa do Hospital da Restauração, sendo aprovado pelo parecer CAAE 32874514.3.0000.5198.

\section{RESULTADOS}

A amostra é caracterizada em sua maioria por mulheres (65\%), as idades variaram entre 22 e 83 anos com média de 44 anos. No que se refere ao estado civil, casados e solteiros obtiveram o mesmo percentual (44\%). Sobre a escolaridade, a maioria tinha $2^{\circ}$ grau incompleto (23\%), seguido por $1^{\circ} \mathrm{grau}$ incompleto.

Referente aos dados clínicos, Tabela 1, a maioria dos pacientes apresentavam entre $1-10 \%$ da SCQ predominantemente de $3^{\circ}$ grau. 0 principal motivo da queimadura foi acidental e verificamos alguns casos de tentativa de autoextermínio e tentativa de homicídio. Quanto ao tempo de queimadura, pouco mais da metade dos pacientes fazia tratamento a menos de um ano. A maioria dos queimados necessitaram de internamento por mais de um mês no hospital, mas pode-se chamar atenção ainda ao quantitativo de pacientes que ficaram internados de 2-4 meses.

O principal agente etiológico foi o álcool seguido de escaldadura e choques elétricos. Em relação às sequelas, verificamos que a grande maioria das queimaduras geraram ambas sequelas (funcionais e estéticas). Além disso, $67 \%$ dos casos houve necessidade de fazer cirurgia para enxertia. A áreas corporais mais acometidas foram os membros superiores seguidos por tronco anterior e abdome.

Na Tabela 2, observa-se a análise do escore de QV segundo os itens e os domínios avaliados. Através dela verifica-se que o domínio no qual os pacientes apresentam melhor qualidade de vida é o de Funções simples, seguido de Relações interpessoais. Ainda, observa-se que o domínio em que os pacientes apresentam pior qualidade de vida é o de Sensibilidade da pele seguido do Trabalho.

Tabela 1. Distribuição de frequências segundo superfície corporal queimada, profundidade, motivo da queimadura, tempo da queimadura, tempo de internamento, necessidade de enxerto, agente etiológico, sequelas e áreas mais acometidas. Recife, 2014.

\begin{tabular}{|c|c|c|c|c|c|}
\hline Variáveis & $\mathbf{N}^{\circ}$ & $\%$ & Variáveis & $\mathbf{N}^{\circ}$ & $\%$ \\
\hline \multicolumn{3}{|c|}{ Superfície corporal queimada } & \multicolumn{3}{|l|}{ Agente etiológico } \\
\hline $1 \%-10 \%$ & 25 & 58,1 & Álcool & 12 & 27,9 \\
\hline $11 \%-20 \%$ & 13 & 30,2 & Escaldadura & 10 & 23,3 \\
\hline $21 \%-30 \%$ & 5 & 11,6 & Eletricidade & 7 & 16,3 \\
\hline Profundidade & & & Chamas & 4 & 9,3 \\
\hline $2^{\circ} \mathrm{grau}$ profundo & 12 & 27,9 & Explosão de gás & 2 & 4,7 \\
\hline $3^{\circ} \mathrm{grau}$ & 25 & 58,1 & Superfície quente & 4 & 9,3 \\
\hline $2^{\circ}$ e $3^{\circ}$ graus & 6 & 14,0 & Outros* & 4 & 9,3 \\
\hline \multicolumn{3}{|l|}{ Motivo da queimadura } & \multicolumn{3}{|l|}{ Sequelas } \\
\hline Acidental & 35 & 81,4 & Funcionais & 2 & 4,7 \\
\hline Tentativa de suicídio & 5 & 11,6 & Estéticas & 6 & 14,0 \\
\hline Tentativa de homicídio & 3 & 7,0 & Ambas & 35 & 81,4 \\
\hline \multicolumn{3}{|c|}{ Tempo da queimadura (anos) } & \multicolumn{3}{|l|}{ Áreas mais acometidas } \\
\hline$<1$ ano & 22 & 51,2 & Face & 9 & 20,9 \\
\hline$>1$ ano & 11 & 25,6 & Pescoço & 7 & 16,3 \\
\hline$>2$ anos & 10 & 23,3 & Tronco anterior & 19 & 44,2 \\
\hline \multicolumn{3}{|c|}{ Tempo de internamento (meses) } & Tronco posterior & 4 & 9,3 \\
\hline$<1$ mês & 12 & 27,9 & Braço (s) & 29 & 67,4 \\
\hline$>1$ mês & 19 & 44,2 & Axila & 5 & 11,6 \\
\hline$>2$ meses & 5 & 11,6 & Mão & 11 & 25,6 \\
\hline$>3$ meses & 2 & 4,7 & Abdome & 13 & 30,2 \\
\hline$>4$ meses & 2 & 4,7 & Nádega & 1 & 2,3 \\
\hline Não foram internados & 3 & 7,0 & Coxa & 2 & 4,7 \\
\hline \multicolumn{3}{|l|}{ Necessidade de enxerto } & Perna & 9 & 20,9 \\
\hline Sim & 29 & 67,4 & Pé & 3 & 7,0 \\
\hline Não & 14 & 32,6 & & & \\
\hline
\end{tabular}

Fonte: Própria pesquisa. 
Ao aplicar o teste de comparação da distribuição da QV entre os domínios avaliados, o resultado apresentou-se significativo $(p<0,001)$. Na análise entre os domínios (dois a dois) observou-se que o Afeto/Imagem corporal e Tratamento são estatisticamente iguais. Além disso, dos domínios Função simples e Relações interpessoais também apresentouse idêntica. Entretanto, a Sensibilidade da pele e o Trabalho não foram estatisticamente iguais a nenhum dos outros domínios avaliados, sendo os domínios que mais afetaram negativamente a qualidade de vida dos pacientes.

No geral, a média do escore de QV dos pacientes avaliados foi igual a 2,9, o que correspondeu a $58 \%$ do escore PSHS-R. Concluímos que os pacientes do estudo têm deficiência em mais da metade da sua QV com a presença das sequelas das queimaduras.

O domínio de afeto e imagem corporal é representado por expressões como "Eu sinto que minha queimadura incomoda outras pessoas", "Às vezes, eu penso que tenho um problema emocional", "Eu fico chateado com o sentimento de solidão", "A aparência das minhas cicatrizes me incomoda", entre outros. Nesse domínio o predomínio de resposta ficou nos dois extremos, no item "não me descreve" que refletiu entre $23-56 \%$ e no item "descreveme muito bem" com frequências entre $21-42 \%$.

Tabela 2. Análise descritiva dos escores da qualidade de vida dos pacientes avaliados por item e domínio. Recife, 2014.

\begin{tabular}{|c|c|c|c|c|c|}
\hline BSHS-R & Intervalo obtido & Mediana & Média & $\begin{array}{l}\text { Desvio } \\
\text { padrão }\end{array}$ & IC (95\%) \\
\hline Total dos 31 itens & $47-145$ & 83,0 & 88,6 & 27,0 & $80,3-96,9$ \\
\hline Média dos 31 itens & $1,5-4,7$ & 2,7 & 2,9 & 0,9 & $2,6-3,1$ \\
\hline Afeto e imagem corporal & $1-5$ & 2,9 & $2,8^{1}$ & 1,3 & $2,4-3,2$ \\
\hline 7 & $1-5$ & 4,0 & 3,2 & 1,7 & $2,6-3,7$ \\
\hline 8 & $1-5$ & 3,0 & 3,1 & 1,6 & $2,6-3,6$ \\
\hline 10 & $1-5$ & 1,0 & 2,4 & 1,7 & $1,9-2,9$ \\
\hline 12 & $1-5$ & 4,0 & 3,4 & 1,7 & $2,8-3,9$ \\
\hline 17 & $1-5$ & 4,0 & 3,3 & 1,8 & $2,8-3,9$ \\
\hline 19 & $1-5$ & 1,0 & 2,4 & 1,8 & $1,8-2,9$ \\
\hline 26 & $1-5$ & 2,0 & 2,5 & 1,7 & $2,0-3,0$ \\
\hline 27 & $1-5$ & 2,0 & 2,5 & 1,7 & $2,0-3,0$ \\
\hline Sensibilidade da pele & $1-5$ & 4,8 & 4,2 & 1,1 & $3,9-4,6$ \\
\hline 6 & $1-5$ & 5,0 & 4,4 & 1,1 & $4,1-4,7$ \\
\hline 16 & $1-5$ & 5,0 & 4,4 & 1,2 & $4,0-4,8$ \\
\hline 18 & $1-5$ & 5,0 & 4,2 & 1,3 & $3,8-4,6$ \\
\hline 25 & $1-5$ & 5,0 & 4,2 & 1,4 & $3,8-4,6$ \\
\hline 29 & $1-5$ & 5,0 & 3,9 & 1,6 & $3,4-4,4$ \\
\hline Funções simples & $1-4$ & 1,8 & $1,8^{2}$ & 0,8 & $1,6-2,1$ \\
\hline 1 & $1-5$ & 2,0 & 2,3 & 1,3 & $1,9-2,7$ \\
\hline 2 & $1-5$ & 1,0 & 1,7 & 1,2 & $1,3-2,1$ \\
\hline 4 & $1-5$ & 1,0 & 1,6 & 1,1 & $1,3-1,9$ \\
\hline 5 & $1-5$ & 1,0 & 1,8 & 1,1 & $1,4-2,1$ \\
\hline Trabalho & $1-5$ & 3,8 & 3,7 & 1,2 & $3,3-4,1$ \\
\hline 3 & $1-5$ & 5,0 & 4,1 & 1,2 & $3,7-4,5$ \\
\hline 9 & $1-5$ & 4,0 & 3,6 & 1,4 & $3,2-4,1$ \\
\hline 13 & $1-5$ & 4,0 & 3,6 & 1,5 & $3,2-4,1$ \\
\hline 15 & $1-5$ & 4,0 & 3,4 & 1,4 & $2,9-3,8$ \\
\hline Tratamento & $1-5$ & 2,4 & $2,6^{1}$ & 1,2 & $2,2-2,9$ \\
\hline 11 & $1-5$ & 2,0 & 2,5 & 1,5 & $2,0-2,9$ \\
\hline 20 & $1-5$ & 2,0 & 2,6 & 1,7 & $2,1-3,2$ \\
\hline 21 & $1-5$ & 1,0 & 2,1 & 1,6 & $1,7-2,6$ \\
\hline 23 & $1-5$ & 3,0 & 2,8 & 1,6 & $2,3-3,3$ \\
\hline 31 & $1-5$ & 3,0 & 3,0 & 1,7 & $2,4-3,5$ \\
\hline Relações interpessoais & $1-5$ & 1,6 & $2,1^{2}$ & 1,3 & $1,7-2,5$ \\
\hline 14 & $1-5$ & 1,0 & 2,0 & 1,7 & $1,5-2,5$ \\
\hline 22 & $1-5$ & 1,0 & 2,1 & 1,7 & $1,6-2,6$ \\
\hline 23 & $1-5$ & 3,0 & 2,8 & 1,6 & $2,3-3,3$ \\
\hline 28 & $1-5$ & 1,0 & 2,1 & 1,7 & $1,6-2,6$ \\
\hline 30 & $1-5$ & 1,0 & 1,7 & 1,4 & $1,2-2,1$ \\
\hline
\end{tabular}

Fonte: Própria pesquisa. 
No que tange à sensibilidade da pele, os itens são os seguintes: "Minha pele está mais sensível agora do que antes", "Ficar no sol me incomoda", "Eu não posso sair para fazer atividades quando está calor," "O calor me incomoda", "Fico incomodado por não poder ficar exposto ao sol". Referente a esse domínio as respostas encontram-se predominantes no item "Descreve-me muito bem" com respostas entre 60-74\% (Tabela 3).
Sobre o domínio habilidades para funções simples os questionamentos são descritos como: "Amarrar sapatos, fazer laços, etc", "Sentar-se e levantar-se de cadeiras", "Tomar banho sem ajuda" "Vestir-se sem ajuda". Referente aos itens citados, a maior frequência foi o "Nenhuma dificuldade" (Tabela 4).

Tabela 3. Distribuição das frequências de respostas aos itens do domínio afeto/ imagem corporal e sensibilidade da pele da BSHS-R para amostra estudada ( $\mathrm{n}=43)$. Recife, 2014.

\begin{tabular}{|c|c|c|c|c|c|}
\hline $\begin{array}{l}\text { Itens } \\
\text { (Afeto e Imagem corporal) }\end{array}$ & Não me Descreve & $\begin{array}{c}\text { Descreve-me um } \\
\text { pouco }\end{array}$ & $\begin{array}{c}\text { Descreve-me mais } \\
\text { ou menos }\end{array}$ & Descreve-me bem & $\begin{array}{c}\text { Descreve-me } \\
\text { muito bem }\end{array}$ \\
\hline $\begin{array}{l}\text { 7. Eu sinto que minha queimadura } \\
\text { incomoda outras pessoas }\end{array}$ & $13(30,2 \%)$ & $5(11,6 \%)$ & $3(7 \%)$ & $4(9,3 \%)$ & $18(41,9 \%)$ \\
\hline $\begin{array}{l}\text { 8. Às vezes, eu penso que tenho } \\
\text { um problema emocional (tristeza, } \\
\text { depressão, etc) }\end{array}$ & $10(23,3 \%)$ & $5(11,6 \%)$ & $8(18,6 \%)$ & $5(11,6 \%)$ & $15(43,9 \%)$ \\
\hline $\begin{array}{l}\text { 10. Eu fico chateado com o } \\
\text { sentimento de solidão }\end{array}$ & $22(51,2 \%)$ & $4(9,3 \%)$ & $4(9,3 \%)$ & $4(9,3 \%)$ & $9(20,9 \%)$ \\
\hline $\begin{array}{l}\text { 12. Às vezes, eu gostaria de } \\
\text { esquecer que minha aparência } \\
\text { mudou }\end{array}$ & $12(27,9 \%)$ & $1(2,3 \%)$ & $5(11,6 \%)$ & $6(14 \%)$ & $19(44,2 \%)$ \\
\hline $\begin{array}{l}\text { 17. A aparência das minhas } \\
\text { cicatrizes me incomoda }\end{array}$ & $14(32,6 \%)$ & $3(7 \%)$ & $2(4,7 \%)$ & $3(7 \%)$ & $21(48,8 \%)$ \\
\hline $\begin{array}{l}\text { 19. Minha aparência me incomoda } \\
\text { muito }\end{array}$ & $24(55,8 \%)$ & $3(7 \%)$ & $4(9,3 \%)$ & 0,0 & $12(27,9)$ \\
\hline $\begin{array}{l}\text { 26. Eu me sinto triste e deprimido } \\
\text { com frequência }\end{array}$ & $21(48,8 \%)$ & $4(9,3 \%)$ & $5(11,6 \%)$ & $4(9,3 \%)$ & $9(20,9 \%)$ \\
\hline 27. Eu me sinto preso, sem saída & $20(46,5 \%)$ & $4(9,3 \%)$ & $6(14 \%)$ & $4(9,3 \%)$ & $9(20,9 \%)$ \\
\hline \multicolumn{6}{|l|}{ Itens (sensibilidade da pele) } \\
\hline $\begin{array}{l}\text { 6. Minha pele está mais sensível } \\
\text { agora do que antes }\end{array}$ & $3(7 \%)$ & $2(4,7 \%)$ & $1(2,3 \%)$ & $10(23,3 \%)$ & $27(62,8 \%)$ \\
\hline 16. Ficar no sol me incomoda & $3(7 \%)$ & $2(4,7 \%)$ & $2(4,7 \%)$ & $4(9,3 \%)$ & $32(74,4 \%)$ \\
\hline $\begin{array}{l}\text { 18. Eu não posso sair para fazer } \\
\text { atividades quando está calor }\end{array}$ & $3(7 \%)$ & $3(7 \%)$ & $3(7 \%)$ & $6(14 \%)$ & $28(65,1 \%)$ \\
\hline 25.0 calor me incomoda & $3(7 \%)$ & $4(9,3 \%)$ & $1(2,3 \%)$ & $4(9,3 \%)$ & $31(72,1 \%)$ \\
\hline $\begin{array}{l}\text { 29. Fico incomodado por não } \\
\text { poder ficar exposto ao sol }\end{array}$ & $8(18,6 \%)$ & $2(4,7 \%)$ & $1(2,3 \%)$ & 6 (14\%) & $26(60,5 \%)$ \\
\hline
\end{tabular}

Fonte: Própria pesquisa.

Tabela 4. Distribuição das frequências de respostas aos itens dos domínios habilidades para funções simples e trabalho da BSHS-R para amostra estudada ( $\mathrm{n}=43$ ). Recife, 2014.

\begin{tabular}{l|c|c|c|c|c}
\hline Itens (funções simples) & $\begin{array}{c}\text { Nenhuma } \\
\text { dificuldade }\end{array}$ & Pouca dificuldade & $\begin{array}{c}\text { Mais ou menos } \\
\text { dificuldade }\end{array}$ & $\begin{array}{c}\text { Muita } \\
\text { dificuldade }\end{array}$ & $\begin{array}{c}\text { Dificuldade } \\
\text { exagerada }\end{array}$ \\
\hline 1. Amarrar sapatos, fazer laços, etc & $17(39,5 \%)$ & $9(20,9 \%)$ & $9(20,9)$ & $4(9,3 \%)$ & $4(9,3 \%)$ \\
\hline 2. Sentar-se e levantar-se de cadeiras & $30(69,8 \%)$ & $3(7 \%)$ & $4(9,3 \%)$ & $4(9,3 \%)$ & $2(4,7 \%)$ \\
\hline 4. Tomar banho sem ajuda & $31(72,1 \%)$ & $2(4,7 \%)$ & $7(16,3 \%)$ & $2(4,7 \%)$ & $1(2,3 \%)$ \\
\hline 5. Vestir-se sem ajuda & $26(60,5 \%)$ & $4(9,3 \%)$ & $11(25,6 \%)$ & $1(2,3 \%)$ & $1(2,3 \%)$ \\
\hline Itens (Trabalho) & $\begin{array}{c}\text { Não me } \\
\text { Descreve }\end{array}$ & $\begin{array}{c}\text { Descreve-me um } \\
\text { pouco }\end{array}$ & $\begin{array}{c}\text { Descreve-me } \\
\text { mais ou menos }\end{array}$ & Descreve-me & $\begin{array}{c}\text { Descreve-me } \\
\text { Muito Bem }\end{array}$ \\
\hline $\begin{array}{l}\text { 3. Voltar ao trabalho, fazendo suas } \\
\text { tarefas como antes* }\end{array}$ & $3(7 \%)$ & 0,0 & $10(23,3 \%)$ & $6(14 \%)$ & $24(55,8)$ \\
\hline $\begin{array}{l}\text { 9. Minha queimadura tem causado } \\
\text { problemas para eu fazer minhas } \\
\text { tarefas no meu trabalho e em casa }\end{array}$ & $6(14 \%)$ & $3(7 \%)$ & $8(18,6 \%)$ & $8(18,6 \%)$ & $18(41,9 \%)$ \\
\hline $\begin{array}{l}\text { 13. A queimadura afetou minha } \\
\text { capacidade para trabalhar }\end{array}$ & $9(20,9 \%)$ & $1(2,3 \%)$ & $6(14 \%)$ & $8(18,6 \%)$ & $19(44,2 \%)$ \\
\hline $\begin{array}{l}\text { 15. Minha queimadura interfere nas } \\
\text { minhas tarefas do trabalho e em casa }\end{array}$ & $7(16,3)$ & $4(9,3 \%)$ & $10(23,3 \%)$ & $11(25,6 \%)$ & $11(25,6 \%)$ \\
\hline
\end{tabular}

Fonte: Própria pesquisa. 
No domínio relacionado ao Trabalho, tabela 4, foram usados os itens "Voltar ao trabalho, fazendo suas tarefas como antes", "Minha queimadura tem causado problemas para eu fazer minhas tarefas no meu trabalho e em casa", "A queimadura afetou minha capacidade para trabalhar," "Minha queimadura interfere nas minhas tarefas do trabalho e em casa". A resposta mais frequente foi "Descreve-me muito bem".

As relações interpessoais também foi um dos domínios estudados, no qual alguns de seus itens são: "Eu não tenho vontade de estar junto dos meus amigos", "Eu prefiro ficar sozinho do que com a minha família”, "Eu não tenho ninguém para conversar sobre os meus problemas". A maioria das respostas se concentrou no item "Não me descreve" (Tabela 5).

Dos itens relacionados ao domínio "Tratamento" na Tabela 5, podemos citar: "Eu tenho dificuldade de cuidar da minha queimadura como foi orientado", "Cuidar da minha queimadura dificulta fazer outras coisas que são importantes para mim", "Eu gostaria de não ter que fazer tantas coisas para cuidar da minha queimadura". Relacionados a estes itens as maiores frequências foram as ditas "Não me descreve" (32,6 - 58,1\%).

\section{DISCUSSÃO}

No presente estudo, as mulheres foram maioria, o que discorda de outra pesquisa a qual tive como maior prevalência os homens ${ }^{10}$. Isso pode estar relacionado aos afazeres domésticos da mulher ou mesmo as atividades no trabalho no caso de cozinheira. As idades encontradas variaram entre 22 e 83 anos, com uma média de 44 anos, semelhante ao estudo que caracterizou os pacientes internados por queimaduras, que a idade variou entre 18 e 76 anos, e teve uma média de 41 anos. Os indivíduos que se enquadram nesta faixa etária são pessoas economicamente ativas, o que causa problemas nos aspectos econômicos e sociais ${ }^{11}$. Vale salientar que esses problemas afetam não só o indivíduo, mas também sua família e/ou dependentes.

O nível de escolaridade dos entrevistados era baixo, apresentando a maioria $2^{\circ}$ grau incompleto. Outro estudo também obteve o nível de escolaridade baixo, $47,6 \%$ possuíam o primeiro grau incompleto ou eram analfabetos ${ }^{11}$. Pode-se concluir que a pouca escolaridade pode ser um dos fatores de risco para queimaduras.

Tabela 5. Distribuição das frequências de respostas aos itens dos domínios relações interpessoais e tratamento da BSHS-R para amostra estudada ( $n=43)$. Recife, 2014.

\begin{tabular}{|c|c|c|c|c|c|}
\hline Itens (Relações interpessoais) & Não me Descreve & $\begin{array}{l}\text { Descreve-me um } \\
\text { pouco }\end{array}$ & $\begin{array}{l}\text { Descreve-me } \\
\text { mais ou menos }\end{array}$ & Descreve-me Bem & $\begin{array}{l}\text { Descreve-me } \\
\text { Muito Bem }\end{array}$ \\
\hline $\begin{array}{l}\text { 14. Eu não tenho vontade de estar } \\
\text { junto dos meus amigos }\end{array}$ & $30(69,8 \%)$ & $1(2,3 \%)$ & $2(4,7 \%)$ & $1(2,3 \%)$ & $9(20,9 \%)$ \\
\hline $\begin{array}{l}\text { 22. Eu prefiro ficar sozinho do que } \\
\text { minha família }\end{array}$ & $30(69,8 \%)$ & 0 & $2(4,7 \%)$ & $1(2,3 \%)$ & $10(23,3 \%)$ \\
\hline $\begin{array}{l}\text { 24. Eu não gosto de maneira } \\
\text { como a minha família age quando } \\
\text { estou por perto }\end{array}$ & $31(72,1 \%)$ & $2(4,7 \%)$ & $1(2,3 \%)$ & $5(11,6 \%)$ & $4(9,3 \%)$ \\
\hline $\begin{array}{l}\text { 28. Eu não sinto vontade de } \\
\text { visitar outras pessoas }\end{array}$ & $28(65, \%)$ & $3(7 \%)$ & $1(2,3 \%)$ & $3(7 \%)$ & $8(18,6 \%)$ \\
\hline $\begin{array}{l}\text { 30. Eu não tenho ninguém } \\
\text { para conversar sobre os meus } \\
\text { problemas }\end{array}$ & $34(79,1 \%)$ & $1(2,3 \%)$ & $2(4,7 \%)$ & 0 & $6(14 \%)$ \\
\hline \multicolumn{6}{|l|}{ Itens (tratamento) } \\
\hline $\begin{array}{l}\text { 11. Eu tenho dificuldade de cuidar } \\
\text { da minha queimadura como foi } \\
\text { orientado }\end{array}$ & $20(46,5 \%)$ & $3(7 \%)$ & $4(9,3 \%)$ & $11(25,6 \%)$ & $5(11,6 \%)$ \\
\hline $\begin{array}{l}\text { 20. É um incomodo cuidar da } \\
\text { minha queimadura }\end{array}$ & $18(41,9 \%)$ & $4(9,3 \%)$ & $4(9,3 \%)$ & $6(14 \%)$ & $11(25,6 \%)$ \\
\hline $\begin{array}{l}\text { 21. Existem coisas que me } \\
\text { disseram para fazer em minhas } \\
\text { queimaduras que eu não gosto }\end{array}$ & $25(58,1 \%)$ & $6(14 \%)$ & $3(7 \%)$ & $1(2,3 \%)$ & $8(18,6 \%)$ \\
\hline $\begin{array}{l}\text { 23. Cuidar da minha queimadura } \\
\text { dificulta fazer outras coisas que } \\
\text { são importantes para mim }\end{array}$ & $17(39,5 \%)$ & $4(9,3 \%)$ & $4(9,3 \%)$ & $9(20,9 \%)$ & $9(20,9 \%)$ \\
\hline $\begin{array}{l}\text { 31. Eu gostaria de não ter que } \\
\text { fazer tantas coisas para cuidar da } \\
\text { minha queimadura }\end{array}$ & $14(32,6 \%)$ & $6(14 \%)$ & $4(9,3 \%)$ & $6(14 \%)$ & $13(30,2 \%)$ \\
\hline
\end{tabular}

Fonte: Própria pesquisa. 
Sobre os dados clínicos das queimaduras constatou-se que mais da metade da amostra tiveram entre $1-10 \%$ da SCQ, o que pode parecer pouco, porém as queimaduras de $3^{a}$ grau também prevaleceram, potencializando a gravidade dos casos. Outras pesquisas realizadas ${ }^{12}$ evidenciaram maior número de pacientes com queimaduras de $2^{\circ} \mathrm{grau}$, essa divergência pode ser devido ao fato de o hospital da presente pesquisa receber pacientes de alta complexidade, sendo referência para toda região Nordeste. Corroborando com este estudo, uma pesquisa que caracterizou pacientes de uma Unidade de Terapia Intensiva de queimados também teve como maioria (70\%) as queimaduras de $3^{\circ} \mathrm{grau}^{11}$.

A principal causa de queimadura foi, predominantemente, acidental. Constatou-se, portanto, o elevado índice de acidentes que resultam em queimaduras. É importante reforçar a prevenção de queimaduras, pois educar a população sobre as formas de prevenção é uma responsabilidade dos profissionais de saúde e educação, bem como instituições como escolas e empresas, que podem desenvolver trabalhos para conscientizar os adultos e educar as crianças sobre formas de prevenção e primeiros socorros ${ }^{13}$.

É salutar apontar para as tentativas de autoextermínio, no qual todos os casos ocorreram em mulheres, concordando com dados do estudo sobre tentativas de autoextermínio por queimaduras, o qual descreve que diferentes fatores podem influenciar na incidência, como idade, época do ano, sexo, condição social, e podem estar ligadas também a alterações emocionais e hormonais, além disso, existe um desconhecimento sobre as consequências e sequelas de queimaduras ${ }^{14}$.

0 percentual elevado de tempo de internamento maior que um mês mostra que as queimaduras são um importante problema de saúde pública. No estudo da evolução financeira do setor de queimados mostra que, de 2002 a 2010, o Nordeste dispensou 20.924 Autorizações de Internação Hospitalar (AlH) e recebeu do governo federal, para tratamento de queimados nos hospitais, cerca de $\mathrm{R} \$ 50.914 .120$ nos nove anos da pesquisa. Desta forma, evidencia-se o alto grau de complexidade neste segmento, possuindo altos custos e necessidades financeiras crescentes ${ }^{15}$.

Quanto ao tempo de tratamento dos pacientes, incluindo o tempo de reabilitação após a alta hospitalar, quase metade dos pacientes faziam tratamento há mais de um ano. A volta das atividades cotidianas acontece gradualmente na vida dos indivíduos, logo, quanto mais recente é o fato mais doloroso para a pessoa, principalmente porque precisa se adaptar às sequelas, como as limitações motoras e cicatrizes ${ }^{16}$.

Referente ao agente causador da queimadura, o álcool foi o principal seguido das lesões por escaldadura, esses dados corroboram com a literatura que evidencia mesma ordem de resultados ${ }^{10}$.

As sequelas eram funcionais ou estéticas, e a grande maioria dos estudados apresentavam os dois tipos. As sequelas físicas (cicatrizes ou limitações) afetam o indivíduo negativamente, influenciando na capacidade para suas atividades laborais, para o retorno ao trabalho e para o relacionamento interpessoal ${ }^{16}$.

Mais da metade dos pacientes necessitaram de cirurgias para enxerto. Esse procedimento está indicado para todas as queimaduras de $2^{\circ}$ e $3^{\circ}$ grau de forma precoce para evitar retrações e minimizar sequelas, o que é disposto no estudo realizado em Fortaleza, no qual $60 \%$ dos pacientes realizaram enxerto ${ }^{17}$.

No que se refere à escala de qualidade de vida, a média dos 31 itens avaliados foi 2,9, que correspondeu a $58 \%$ de pior QV. Quando divididos os domínios, é possível avaliar separadamente o nível de qualidade de cada um deles. Neste estudo, os piores níveis estão nos domínios "sensibilidade da pele" e "trabalho". Em outra pesquisa, apesar de utilizar uma forma estatística diferente (valor de alfa de (robach), traz dados semelhantes em relação ao domínio "trabalho", que ficou em primeiro lugar como pior QV e, em seguida, estava o "afeto e imagem corporal", diferentemente desta pesquisa que este domínio não teve uma média tão alta em relação aos demais ${ }^{7}$.

A melhor QV se enquadrou no domínio "Funções simples" concordando com a pesquisa que também o descreve como o de melhor estado de saúde ${ }^{7}$. Porém, a partir da comparação de Mann-Whitney realizada no presente trabalho, as "Funções simples" não tiveram diferença significativa comparada às "Relações interpessoais", mostrando que esses dois domínios não sofrem grande impacto.

0 item 6 (Minha pele está mais sensível agora do que antes) e o 16 (Ficar no sol me incomoda) foram os que obtiveram maior média, ou seja, piores resultados. Corroborando com Nicolozi (2012) que utilizou a mesma escala para avaliar a QV de adolescentes, que também obteve sua maior média $(2,4)$ no item 6 . Os itens $3,18,25$ e 29 também obtiveram médias elevadas, todos relacionados à sensibilidade da pele, reforçando que neste domínio a QV foi mais afetada.

Sobre o domínio Afeto e Imagem corporal, a frequência de respostas foi no descritor "não me descreve", se concentrando nos itens "Eu fico chateado com sentimento de solidão" "Minha aparência me incomoda". Concordando com outra pesquisa ${ }^{10}$, na qual as maiores frequências de respostas nesse domínio também foi "Não me descreve".

É importante salientar a frequência elevada de respostas "Descreve-me muito bem" que concentrou das respostas no item "A aparência das minhas cicatrizes me incomoda" e em "As vezes eu penso que tenho um problema emocional". O impacto emocional após as queimaduras pode contribuir negativamente no processo de reabilitação, afetando o bem-estar, a qualidade de vida e a adaptação psicossocial ${ }^{18}$.

Na sensibilidade da pele as respostas se concentraram no descritor "Descreve-me muito bem", este último percentual corresponde ao item "Ficar no sol me incomoda". Isso mostra que as queimaduras trazem muitos incômodos mesmo após a alta hospitalar. As sequelas resultam em limitações funcionais que afetam a capacidade do indivíduo, uma delas é a sensibilidade da pele, tornando-se um fator que dificulta mais ainda a volta às atividades cotidianas ${ }^{16}$. 
Para desenvolver tarefas simples, o maior percentual de pessoas respondeu que os itens não os descreviam, ou seja, não tinham dificuldade em desenvolver atividades como, por exemplo, tomar banho sem ajuda. Esse resultado é semelhante a uma pesquisa que avaliou pacientes queimados após alta hospitalar ${ }^{8}$.

A volta ao trabalho é um dos fatores que mais tem impacto na vida do indivíduo. No domínio relacionado ao trabalho, as respostas se concentraram no descritor "descreve-me muito bem", tendo como respostas a maior dificuldade para "voltar ao trabalho e fazer suas tarefas como antes". Nesse aspecto, pode-se verificar diferentes prejuízos relacionados também ao gênero, no caso do homem afeta não só a capacidade de trabalho, mas também a hierarquia familiar, deixando de ser provedor da casa; já para as mulheres, além da dificuldade de voltar ao trabalho, afeta na realização de tarefas domésticas, socialmente mais associadas as elas ${ }^{10}$.

Um estudo sobre fatores psicossociais que interferem na reabilitação dos queimados discorre que quanto maior a SCQ maiores serão as dificuldades para retorno ao trabalho, além disso, as limitações sociais e ocupacionais aumentam o risco para desenvolver depressão ${ }^{18}$.

As relações com familiares e amigos não foram afetadas após a queimadura, visto que a resposta "não me descreve" foi a mais prevalente entre os itens do domínio "Relações interpessoais", concordando com um estudo que avaliou a QV após a alta hospitalar, que mostrou que após o trauma não houve percepção de problemas nesse aspecto8 .

No domínio "Tratamento" foi evidenciado que cuidar da queimadura não se mostrou um incomodo. Um trabalho sobre o significado das ocupações após acidentes por queimaduras constatou que o tratamento passou a ser a principal ocupação dos pacientes, visando a recuperação da sua saúde, e que as atividades como fazer curativos, realizar consultas e fazer fisioterapia já faziam parte do seu cotidiano ${ }^{19}$.

Contudo, alguns pacientes relataram ter muitas dificuldades com o quesito Tratamento. Isso pode ser explicado pelos diversos fatores envolvidos no processo de Tratamento/Reabilitação, como: procedimentos dolorosos, engajamento no autocuidado, disciplina e expectativas irreais na reabilitação ${ }^{18}$.

\section{CONCLUSÃO}

É consenso que as queimaduras são um problema de relevância pública, e as sequelas geradas por elas trazem consequências nos aspectos físicos, psíquicos e sociais. A QV das pessoas que desenvolveram sequelas de queimaduras é afetada diretamente pelas mudanças relacionadas ao tratamento e a reabilitação.

Para melhorar a QV do paciente com sequelas de queimadura é necessária a atuação de uma equipe multidisciplinar para interagir nos diferentes aspectos afetados, o que não é uma tarefa fácil. A saída do hospital é mais difícil para aquele paciente que desenvolveu sequelas, por isso deve ser acompanhado também fora dele. Além disso, os profissionais devem visar a prevenção, cura, proteção ao paciente e principalmente a promoção da saúde, para tanto é importante que haja orientações corretas sobre o processo de reabilitação e prevenção de outras sequelas.

Além do tratamento e reabilitação, que são decisivos para um bom resultado após a lesão, é essencial dar ênfase na prevenção das queimaduras. Os profissionais de saúde devem realizar educação permanente para conscientizar sobre os perigos e consequências de uma queimadura.

\section{REFERÊNCIAS}

1. BORGES R.T. Tentativa de autoextermínio por fogo: traumas, sofrimento social e Promoção da pessoa humana / Rafaele Teixeira Borges. - 2013.66 f. Dissertação (mestrado) Universidade de Fortaleza, 2013.

2. SOCIEDADE AMERICANA DE QUEIMADURAS. Disponível em: <www.ameriburn.org/resources_factsheet.php>. Acesso em: 13 jul. 2013.

3. SOCIEDADE BRASILEIRA DE QUEIMADURAS. Conceito e causas. Classificação de queimaduras. Disponível em: http:// sbqueimaduras.org.br/queimaduras-conceito-e-causas/ classificacoes-de-queimaduras/\#sthash.9w60mfUt.dpuf. Acesso em 10 nov. 2014.

4. GAWRYSZEWSKI V. P.; et al. Atendimentos decorrentes de queimaduras em serviços públicos de emergência no Brasil. Cad. Saúde Pública, Rio de Janeiro, 28(4):629-640, abr, 2012.

5. LEÃO C. E. G.; et al. Epidemiologia das queimaduras no estado de Minas Gerais. Revista Bras. Cir. Plást. 26(4): 573-7, 2011.

6. LAPORTE G. A.; LEONARD D. F. Transtorno de estresse póstraumático em pacientes com sequelas de queimaduras Revista Bras Queimaduras 9(3):105-14. 2010.

7. FERREIRA E. Adaptação cultural de "Burn Specific Health Scale-Revised" (BSHS-R): versão para brasileiros que sofreram queimaduras. Dissertação de mestrado apresentado a Escola de Enfermagem de Ribeirão Preto- SP, 2006.

8. P. JUNIOR G. F.; VIEIRA A. C. P.; ALVES G. M. G. Avaliação da qualidade de vida de indivíduos queimados pós alta hospitalar. Revista Bras Queimaduras, 9(4):140-5, 2010.

9. FRANCISCHETTI C. E.; CAMARGO L. S. G.; SANTOS N. C. Qualidade de vida, sustentabilidade e educação financeira. Revista de Finanças e Contabilidade da Unimep - REFICONT - v. 1, n. 1, Jul/Dez - 2014.

10. BRASIL. Ministério da Saúde. Secretaria de Atenção à Saúde. Departamento de Atenção Especializada. Cartilha para tratamento de emergência das queimaduras/ Ministério da Saúde, Secretaria de Atenção à Saúde, Departamento de Atenção Especializada. - Brasília : Editora do Ministério da Saúde, 2012. 20 p. : il. - (Série F. Comunicação e Educação em Saúde).

11. COSTA M. C. S.; ROSSI L. A.; DANTAS R. A. S.; TRIGUEIROS L. F. Imagem corporal e satisfação no trabalho entre adultos em reabilitação de queimaduras. Cogitare Enferm. Abr/Jun; 15(2):209-16, 2010. 
12. CAMUCI M. B. Caracterização epidemiológica de pacientes adultos internados em uma unidade de terapia intensiva de queimados. Cogitare enferm. Jan/mar; 19(1):78-83, 2012.

13. SANTANA C. M. L.; BRITO C. F. B.; COSTA A. C. S. M. Importância da fisioterapia na reabilitação do paciente queimado. Revista Bras Queimaduras, 11(4):240-5, 2012.

14. CARVALHO I.D DE, FREITAS M.C.V, MACIEIRA L. Tentativa de autoextermínio com queimaduras - CTQ-HFA-RJ. Revista Bras Queimaduras, 13(2):95-8, 2014.

15. PESCUMA JUNIOR A.; MENDES A.; ALMEIDA P. C. C. A evolução financeira do setor de queimados, sua legitimidade, seu financiamento e sua complexidade durante o período de 2002 a 2010. PESQUISA \& DEBATE, SP, volume 24, número 1(43) pp. 121-136, jan-jun. 2013.

16. SCHIAVON V. C.; et al. Reabilitação e retorno ao trabalho após queimaduras ocupacionais. Revista Enferm. Cent. O. Min. jan/ abr, 4(1):929-939, 929, 2014.

17. ALBUQUERQUE M.L.L.; et al. Análise dos pacientes queimados com sequelas motoras em um hospital de referência na cidade de Fortaleza-CE. Revista Bras Queimaduras, 9(3):89-94, 2010.

18. GONÇALVES N.; et al. Fatores biopsicossociais que interferem na reabilitação de vítimas de queimaduras: revisão integrativa da literatura. Revista Latino-Am. Enfermagem. 19(3): [09 telas] maio-jun, 2012.

19. MONTEIRO L. S. Sobre o significado das ocupações após o acidente por queimaduras. SSN 0104-4931. Cad. Ter. Ocup. UFSCar, São Carlos, v. 22, n. 2, p. 305-315, 2014. 